\title{
CORRESPONDENCE
}

\section{New data system to galvanize Brazil's conservation efforts}

The Global Environment Facility last month endorsed an ambitious project to construct a Brazilian national biodiversity information system. This will be tailored to the needs of key decision-makers in the government and in the private sector (see go.nature.com/ OYiHOj).

Brazil contains roughly $60 \%$ of the Amazon rainforest and $15-20 \%$ of the world's biodiversity. But the country holds only $1 \%$ of the scientific data stored in biological collections worldwide. This poor documentation is holding back efforts to plan effective conservation strategies and to manage valuable biological resources.

The proposed new system will differ from existing initiatives, which are designed mainly to serve the scientific community. It will be coordinated by the government's Ministry of Science and Technology, and will be built in consultation with policy-makers, planners and other stakeholders. A range of visualization and analysis tools will allow decision-makers to combine the new biodiversity information with other socio-economic and physical databases. The information will be freely available, which should increase accountability and usability.

Brazil's deforestation has been decreasing; the economy is growing; and there is the political will to tackle the country's pressing environmental problems. The progress of the new initiative will be watched across the developing world, where other biodiversity-rich nations face many of the same issues of poor data availability and multiple threats to biodiversity.

Ana C. M. Malhado Federal University of Viçosa, 36570-000 Viçosa, Minas Gerais, Brazil

e-mail: anaclaudiamalhado@gmail.com
Richard J. Ladle School of Geography and the Environment, University of Oxford, South Parks Road, Oxford OX13QY,UK

\section{Green development credits to foster global biodiversity}

Innovative financial mechanisms

for global biodiversity conservation are a top priority for the tenth meeting of the Conference of the Parties to the Convention on Biological Diversity (CBD) in Japan in October.

Frustrated with nearly 20 years of waiting for promised funds, some countries and environmental organizations are pressing for a 'green development' mechanism, analogous to the Kyoto Protocol's Clean Development Mechanism. This has delivered billions in private-sector funds to reduce greenhouse-gas emissions.

Such a mechanism for conserving biodiversity could unlock comparable volumes of funding by identifying projects for investors interested in supporting conservation activities worldwide. A programme might begin with voluntary participation, offering a 'credit' for the area of land complying with the CBD's objectives of conservation, sustainable use and equitable benefit sharing.

Although this credit would not have a legal application in mitigating a buyer's biodiversity footprint, it would create a transparent, independently verified and quantifiable investment. The absence of such an instrument has long been an obstacle to greater private-sector and individual participation in funding global biodiversity goals.

Success will depend on support from developing countries, notably those with large areas of land in need of ecological restoration. All those responsible for land management - governmental, corporate, non-governmental and community groups, individuals and indigenous people - should benefit equally from the green development mechanism.

Alexander N. James Restauração Florestal, Marituba, Pará, Brazil e-mail: alexander@ restauracaoflorestal.com.br Francis Vorhies Earthmind http://gdm.earthmind.net

\section{Expand scientific input to address environmental effects}

The proposed Intergovernmental Science-Policy Platform on Biodiversity and Ecosystem Services (IPBES) (Nature 465, 525; 2010) should be part of a broader complementary system of scientific input. This would help to coordinate data that fall under the remit of multiple international environmental agencies and agreements. And it would minimize the risks of duplication in scientific review and reporting.

A global consultation of scientists and others, coordinated by DesertNet International and the United Nations Institute for Water, Environment and Health (www.desertnet-international. org), has suggested that an equivalent intergovernmental science-policy panel for land and water issues is needed. Otherwise, important independent questions are likely to be absorbed by the scientific bodies that advise on climate change and biodiversity loss.

Crucial matters may not receive the policy attention they deserve if solely addressed by the Intergovernmental Panel on Climate Change and the proposed IPBES. Examples are the impacts of trends in population growth and demographic bulges; food and energy insecurity; migration; and 'land and water grabbing' by wealthy foreign companies in developing nations.

Lindsay C. Stringer School of Earth and Environment, University of Leeds, Woodhouse Lane, Leeds LS2 9JT, UK e-mail: I.stringer@leeds.ac.uk
Richard J. Thomas United Nations University, Institute for Water, Environment and Health, Hamilton, Ontario I8P 0A1, Canada Mariam Akhtar-Schuster Secretariat DesertNet International, University of Hamburg, 22609 Hamburg, Germany

\section{Call for cooperation to contain damage by Chile's salmon farms}

The Aysén region in southern Chile - a key habitat for several endangered marine species - is under enormous pressure from the country's powerful salmon industry. Chile should follow the lead of nations such as Italy (see Nature 464, 673; 2010), Australia and the United States and urgently consider an integrated, more collaborative approach between its aquaculture industry and conservation policies.

Chile exports US\$2 billion of Atlantic salmon (Salmo salar) every year, and the area taken up by aquaculture is increasing. The magnitude of the salmon farms and their associated noise and pollution are among several threats to local wildlife. Atlantic salmon is an alien predator, with uncharted effects on the endemic fish population and the entire local ecosystem. Nets used to protect the farmed fish are a hazard to marine mammals. The aquacultures also threaten local fisheries and the development of sustainable tourism.

Politicians and the public are largely unaware of these dangers because potential environmental damage by industries is not systematically controlled in Chile. We suggest implementing collaborative efforts between aquaculture industries and local fisheries (see Nature 463, 1007; 2010) and applying stringent environmental controls.

Heike Vester Ocean Sounds, 8312 Henningsvaer, Vestfjord, Norway e-mail: info@ocean-sounds.com Marc Timme Max Planck Institute for Dynamics and Self-Organization, 37073 Göttingen, Germany 